Published in final edited form as:

Epilepsy Behav. 2009 June ; 15(0 1): S11-S16. doi:10.1016/j.yebeh.2009.03.029.

\title{
The psychosocial impact of epilepsy in adults
}

\author{
Bruce Hermann, PhD and \\ Department of Neurology, University of Wisconsin School of Medicine and Public Health, \\ Madison, Wisconsin
}

\author{
Ann Jacoby, PhD \\ Division of Public Health, University of Liverpool School of Population, Community and \\ Behavioural Sciences, Liverpool, UK
}

\begin{abstract}
Although defined by the presence of recurrent seizures, epilepsy can be so much more and can include a very wide range of difficulties in cognition, psychiatric status, and social adaptive functioning. These psychosocial complications of epilepsy have a long history, generating calls for action by national commissions, public health agencies, and special action groups which are briefly summarized here. Next, a brief overview of the prevalence of psychosocial complications of epilepsy in population-based and other non-selected studies is presented. Finally, focusing on the onset and development of psychosocial difficulties, the following points are stressed:

1) neurobiological factors likely contribute to psychosocial problems in a major way, but currently this contribution is poorly understood, and 2) while neurobiological factors may prove important, they operate in a social setting, and therefore a full accounting of the etiology, treatment and prevention of psychosocial problems in epilepsy will require an integrated biopsychosocial model and lifespan perspective.
\end{abstract}

\section{Introduction}

The psychosocial impact of epilepsy in adults will be reviewed briefly in this chapter with a focus on three topics: 1) the scope of the problem, 2) the potential neurobiology of psychosocial problems, and 3) the psychology of psychosocial problems.

\section{Background of Concern}

The complications associated with living with epilepsy have been well recognized and some milestones in the US will be mentioned.

William Lennox [1] was deeply concerned about the psychological and social complications of the epilepsies and in one of his early figures (Figure 1) he captured what he believed to be the several forces that served to adversely affect people with epilepsy, as well as the factors that could provide protection.

In 1978 the Plan for Nationwide Action on Epilepsy [2] was released by the Commission for the Control of Epilepsy and Its Consequences. This Commission represented a panel of national experts from diverse fields that were charged by Congress to survey the status of

Publisher's Disclaimer: This is a PDF file of an unedited manuscript that has been accepted for publication. As a service to our customers we are providing this early version of the manuscript. The manuscript will undergo copyediting, typesetting, and review of the resulting proof before it is published in its final citable form. Please note that during the production process errors may be discovered which could affect the content, and all legal disclaimers that apply to the journal pertain. 
care and treatment of people with epilepsy in America and identify salient needs. In addition to targeted reviews of the literature and consultations with experts, the panel held open hearings around the country to obtain input from patients, their families, and others. The panel was impressed by the complications associated with living with epilepsy and stated: "Possibly the least understood and most neglected aspects of epilepsy are the social, psychological, and behavioral problems that are so common." In their report they noted that over three-fourths had at least one psychosocial problem, over half had mental health problems, almost half had cognitive problems and unemployment rates were double that of the general population. The Commission report set the stage for comprehensive epilepsy clinics and other major developments in epilepsy care and research.

The CDC and its partners including the Epilepsy Foundation, the American Epilepsy Society, and the National Association of Epilepsy Centers held two national meetings dedicated to epilepsy [3,4]. A broad overview of the Living Well Conferences and especially the outcomes from Living Well II has been summarized recently [5]. The public health implications of those meetings have been substantial. Living Well II focused on 4 major content areas that included a) early recognition, diagnosis and treatment, b) epidemiology and surveillance, c) self management, and d) impact of epilepsy on quality of life. From this meeting a diversity of priority recommendations resulted and the progress has been substantial [5].

In March 2007 over 400 researchers, physicians, patients, family members and professional and voluntary health organization leaders gathered for the NIH/NINDS conference entitled Curing Epilepsy 2007: Translating Discoveries into Therapies) [6]. As a result, preventing and reversing the comorbidities of epilepsy was identified as a new critical area for research. The specific benchmark areas resulting from this conference included: 1) prevention of epilepsy and its progression, 2) development of new therapeutic strategies and optimization of current approaches to cure epilepsy, and 3) prevention, limitation and reversal of the comorbidities associated with epilepsy and its treatment. The comorbidities benchmark was a new addition and the specifics regarding this benchmark can be seen at: http:// www.ninds.nih.gov/funding/research/epilepsyweb/2007_benchmarks.htm

\section{The Nature of the Problem}

A wealth of information speaks to the problems that may be faced by people with epilepsy. Three pieces of evidence will be presented here, while many other issues will be touched on in other chapters.

First, contemporary population based investigations have demonstrated several key points. Recent results from the CDC Behavioral Risk Surveillance study [7] summarized population based data derived from 19 states. Compared to controls, adults with a history of active epilepsy were more likely to report fair or poor health, be unemployed or unable to work, live in households with the lowest annual incomes, and have a history of co-occurring medical disorders. Adults with a history of epilepsy and with active epilepsy also reported significantly worse health-related quality of life and were more likely to be obese, physically inactive, and a current smoker. Among adults with a history of epilepsy, $23.7 \%$ reported cost as a barrier to seeking care from a doctor within the past year and a total of $34.9 \%$ of adults with active epilepsy with seizures reported not having seen a neurologist or an epilepsy specialist.

Second, mental health issues have long been a concern and reports from selected populations and tertiary care centers have long reported increased rates of depression and anxiety compared to control populations. Recent population based findings again demonstrate the increased risk of mental health issues in epilepsy [8](Table 1). 
The degree to which these problems are associated specifically with epilepsy compared to other neurological disorders or chronic medical illnesses in general remains to be clarified. Efforts in this regard have begun to appear and, for instance, an increased risk of mood disorder/bipolar symptoms compared to other medical disorders was reported by Ettinger [9] (Figure 2).

These mental health complications are often viewed in a static fashion. The risk of psychiatric comorbidity over the course of the disorder has been inadequately characterized. Recently, Jones et al. [10] reported results from a prospective controlled cohort study that examined psychiatric disorder over a 4 year interval. Consistent with the published literature, rates of DSM-IV axis I disorders were elevated in epilepsy patients at baseline, but there was also a significantly increased number of interval episodes of axis I disorders overall and depression in particular compared to controls, with a trend of increased anxiety disorders, evident even when prior psychiatric history was controlled (Table 2).

Finally, regarding cognition and memory, little population based information is available regarding the cognitive status of adults with epilepsy. However, there is a long history of research that has consistently indicated cognitive disruption is over-represented in some patients with epilepsy, the causes of which include the etiology underlying epilepsy, clinical seizure features (seizure type), EEG abnormalities (transient cognitive impairment-[11]), medications [12] and other factors.

\section{The Neurobiology of Psychosocial Problems}

One factor that must be considered in discussions of the etiology of employment, education, social problems and other psychosocial considerations is the degree of underlying brain pathology that may be present in some patients. This is a rarely discussed consideration in regard to psychosocial problems in epilepsy. The most convincing data in this regard come from careful investigations of surgical candidates prior to surgery.

Lin and collaborators examined cortical thickness in patients with mesial temporal lobe epilepsy who eventually underwent epilepsy surgery with excellent treatment outcomes [13]. Sophisticated neuroimaging procedures demonstrated a surprising degree of distributed brain pathology in these subjects (Figure 3), with cortical thinning that was observed bilaterally in the context of demonstrated unilateral onset of the epilepsy. Similar findings were reported recently by McDonald et al. [14] who also reported widespread cortical thinning in patients with temporal lobe epilepsy.

A complementary finding concerns the status of discrete cerebral structures in unilateral temporal lobe epilepsy and the degree of atrophy in regions of interest reported by Pulsipher et al. [15]. As can be seen in Figure 4, there is a range of atrophy in discrete neural structures in temporal lobe epilepsy.

These volumetric reductions, on their face, would appear to of relevance to the somewhat surprising finding that temporal lobe epilepsy can be associated not only with memory abnormality, but a more widespread pattern of cognitive impairment, a point made by Oyegbile et al. [16].

Subsequent studies have demonstrated specificity of brain-behavior relationships with the distributed brain abnormality resulting in a mosaic of cognitive impairments. While the etiology and progression of these problems remains to be clarified, one cannot help but suspect that such anatomic findings underlie reductions in psychosocial efficiency and that a neuroscience of psychosocial problems may be pursued in a meaningful fashion. Direct investigations of brain status associated with psychosocial problems (employment, marriage, 
social network, income) would appear to be needed. Further, interpersonal interaction/brain structure associations would be of interest given the literature regarding social neuroscience and epilepsy would be well positioned for such investigations.

\section{The Psychology of Psychosocial Problems}

The limits of reductionism, however, can be appreciated when faced by the words of people with epilepsy and their families who face the consequences of epilepsy. When patients and their family members have been carefully interviewed regarding the phenomenology of seizures, the reactions of others, and the social complications of epilepsy, the results have been striking [17] [18] [19] [20].

These issues are international in scope. Tables 3 and 4 represent responses to questions pertaining to feelings of perceived stigma associated with epilepsy, responses we have come to expect in the US, but these findings come from Zambia [21], and this same theme is reflected in other international reviews [22]. In some parts of the world this stigma is not just felt stigma, but may carry fundamental insecurities as demonstrated by Birbeck-including food and water insecurity and personal safety.

Another important psychological component of epilepsy is how the experience of living and dealing with the disorder may affect a person's view of the world and how it works-socalled locus of control. Individuals have views regarding the controllability of events in their lives (be they right or wrong). Those with a so-called external locus of control, whether it be for all events or just some, believe that they have little personal control and such a general outlook is associated with a more passive stance and depressogeneic thinking. Some studies have reported that persons with epilepsy have a more external locus of control compared to persons with other medical disorders or the general population. A more external locus of control was found in children with epilepsy compared to children with diabetes and controls [23], or orthopedic controls [24] or other control populations [25] which has been linked to beliefs about the etiology of adverse events.

\section{Conclusion}

A wealth of evidence attests to the challenges that may be faced with people in the realm of psychosocial function, evidence that has been provided by population based investigations, studies of patients from clinical centers, national commissions, and the words of people with epilepsy themselves [26]. Further investigation is warranted into the neuroscience and psychological dimensions of the psychosocial problems experienced by people with epilepsy.

\section{Moderator Comment}

As highlighted by Lennox [1](Figure 1), the psychosocial ills of people with epilepsy can only be fully understood through consideration of its social reality, alongside the neurobiological and psychological problems discussed above. Epilepsy occurs in a social context within which there are different ways of 'knowing', different social values assigned to people with epilepsy, different healthcare systems and different social structural factors at work. For example, in China and Vietnam, explanations about the etiology of epilepsy draw upon Chinese traditional medicine theories and accompanying notions of 'bodily imbalance', resulting in relatively benign cultural representations [27]; in many African countries, the dominant explanatory model is that of spirit or demonic possession and/or contagion, with accompanying highly negative societal reactions [28,29]; while in the US and Western Europe, the biomedical model predominates and epilepsy is therefore configured as sickness, not sinfulness [30]. These different ways of knowing about epilepsy 
influence lay and professional attitudes towards its everyday management; hence, the psychosocial problems of people with epilepsy - for example, in relation to their educational and employment status - represent a complex intermixing of the neurobiological and psychological with socio-cultural factors.

The argument has been made that increasing alignment with the biomedical model and processes of medicalization of epilepsy worldwide are shifting public attitudes and the social reality of epilepsy for the better, leading to reductions in the psychosocial problems reported by people with epilepsy. Recent studies do highlight improvements over time in public attitudes worldwide, but also continuing misperceptions and negative attitudes [31, 32]; parents', teachers', employers' and health professionals' attitudes have all been found to be problematic [33,34,35,36]. The distinction between 'felt' and 'enacted' stigma [17] is a valuable one for understanding the psychosocial problems of people with epilepsy, since it allows differentiation of an individual's internal response to their condition from external expressions of its current social reality and the resultant formal and formal discriminations that operate. To fully appreciate the psychosocial impact of a diagnosis of epilepsy, we need to take account of the power of social labeling effects and the process of internalization and application to self of negative societal concepts and stereotypes [37].

\section{Group discussion}

- The social stigma of epilepsy remains strong in many parts of the world; and bullying and traumatic life events in childhood, both possible concomitants of stigma, have been shown to be predictors of future psychosocial problems.

- A mechanism for linking neurobiology to social stigma is suggested by animal models. Improved environment has been shown to increase connectivity of brain tissue; conversely, an impoverished environment can produce thinning of brain tissue. If people with epilepsy experience impaired quality of life, including as a response to social stigma, the resultant thinning of the cortex may have significant impacts for psychosocial functioning.

- Rates of psychosocial ill-health have been documented as fairly high in chronic conditions other than epilepsy, raising questions about the way in which societies frame the issue of disability more widely.

- Treatment strategies that fully integrate the neurobiological and psychological dimensions of epilepsy with the social dimensions are likely to be more successful than those which neglect the latter's role.

\section{References}

1. Lennox, WG. Epilepsy and related disorders. Boston: Little, Brown and Co.; 1960.

2. Plan for Nationwide Action on Epilepsy: Report of the Commission for the control of Epilepsy and its Consequences. Bethesda, MD: US Department of Health, Education and Welfare; 1978.

3. Living Well with Epilepsy: Report of the 1997 National Conference on Public Health and Epilepsy. Landover, MD: Epilepsy Foundation; 1998.

4. Living Well with Epilepsy II: Report of the 2003 National Conference on Public Health and Epilepsy: Priorities for a public health agenda on epilepsy. Landover, MD: Epilepsy Foundation; 2004.

5. Austin JK, Carr DA, Hermann BP. Living Well II: a review of progress since 2003. Epilepsy Behav. 2006; 9:386-93. [PubMed: 17074615]

6. NIH. NIH Curing Epilepsy 2007 Conference. 2007In: http://www.ninds.nih.gov/funding/research/ epilepsyweb/curingepilepsy/index.htm 
7. Kobau R, Zahran H, Thurman DJ, Zack MM, Henry TR, Schachter SC, Price PH. Epilepsy surveillance among adults--19 States, behavioral risk factor surveillance system, 2005. MMWR Surveill Summ. 2008; 57:1-20. [PubMed: 18685554]

8. Tellez-Zenteno JF, Patten SB, Jette N, Williams J, Wiebe S. Psychiatric Comorbidity in Epilepsy: A Population-Based Analysis. Epilepsia. 2007

9. Ettinger AB, Reed ML, Goldberg JF, Hirschfeld RM. Prevalence of bipolar symptoms in epilepsy vs other chronic health disorders. Neurology. 2005; 65:535-40. [PubMed: 16116112]

10. Jones JE, Bell B, Fine J, Rutecki P, Seidenberg M, Hermann B. A Controlled Prospective Investigation of Psychiatric Comorbidity in Temporal Lobe Epilepsy. Epilepsia. 2007; 48:23572360. [PubMed: 17651410]

11. Aarts JH, Binnie CD, Smit AM, Wilkins AJ. Selective cognitive impairment during focal and generalized epileptiform EEG activity. Brain. 1984; 107 (Pt 1):293-308. [PubMed: 6421454]

12. Loring DW, Marino S, Meador KJ. Neuropsychological and Behavioral Effects of Antiepilepsy Drugs. Neuropsychol Rev. 2007

13. Lin JJ, Salamon N, Lee AD, Dutton RA, Geaga JA, Hayashi KM, Luders E, Toga AW, Engel J Jr, Thompson PM. Reduced neocortical thickness and complexity mapped in mesial temporal lobe epilepsy with hippocampal sclerosis. Cereb Cortex. 2007; 17:2007-18. [PubMed: 17088374]

14. McDonald CR, Hagler DJ Jr, Ahmadi ME, Tecoma E, Iragui V, Gharapetian L, Dale AM, Halgren E. Regional neocortical thinning in mesial temporal lobe epilepsy. Epilepsia. 2008; 49:794-803. [PubMed: 18266751]

15. Pulsipher DT, Seidenberg M, Morton JJ, Geary E, Parrish J, Hermann B. MRI volume loss of subcortical structures in unilateral temporal lobe epilepsy. Epilepsy Behav. 2007; 11:442-9. [PubMed: 17996640]

16. Oyegbile TO, Dow C, Jones J, Bell B, Rutecki P, Sheth R, Seidenberg M, Hermann BP. The nature and course of neuropsychological morbidity in chronic temporal lobe epilepsy. Neurology. 2004; 62:1736-42. [PubMed: 15159470]

17. Scambler, G. Epilepsy (The Experience of Illness Series). London: Routledge; 1989.

18. Schneider, J.; Conrad, P. Having Epilepsy: the Experience and Control of Illness. Philadelphia: Temple University Press; 1983.

19. Schachter, SC. Brainstorms. Oxford: Oxford University Press; 2008. Epilepsy in Our Words: Personal Accounts of Living with Seizures.

20. Mittan, RJ. Fear of seizures. In: Whitman, S.; Hermann, BP., editors. Psychopathology in epilepsy: Social dimensions. New York: Oxford University Press; 1982. p. 90-121.

21. Birbeck G, Chomba E, Atadzhanov M, Mbewe E, Haworth A. The social and economic impact of epilepsy in Zambia: a cross-sectional study. Lancet Neurol. 2007; 6:39-44. [PubMed: 17166800]

22. Schachter, SC.; Andermann, LF. Brainstorms. New York: Oxford University Press; 2008. Epilepsy in Our World: Stories of Living with Seizures from Around the World.

23. Matthews WS, Barabas G, Ferrari M. Emotional concomitants of childhood epilepsy. Epilepsia. 1982; 23:671-81. [PubMed: 7173134]

24. Shagena MM, Sandler HK, Perrin EC. Concepts of illness and perception of control in healthy children and in children with chronic illnesses. J Dev Behav Pediatr. 1988; 9:252-6. [PubMed: 3225320]

25. Asadi-Pooya AA, Schilling CA, Glosser D, Tracy JI, Sperling MR. Health locus of control in patients with epilepsy and its relationship to anxiety, depression, and seizure control. Epilepsy Behav. 2007; 11:347-50. [PubMed: 17904913]

26. Gehlert S. Perceptions of control in adults with epilepsy. Epilepsia. 1994; 35:81-8. [PubMed: 8112261]

27. Jacoby A, Wang W, Dang Vu T, Wu J, Snape D, et al. Meanings of epilepsy in its sociocultural context and implications for stigma: Findings from ethnographic studies in local communities in China and Vietnam. Epilepsy \& Behaviour. 2007; 12:286-97.

28. JilekAall L, Jilek M, Kaaya J, et al. Psychosocial study of epilepsy in Africa. Soc Sci Med. 1997; 45:783-795. [PubMed: 9226801]

29. Birbeck GL. Seizures in rural Zambia. Epilepsia. 2000; 41(3):277-81. [PubMed: 10714398] 
30. Conrad, P.; Schneider, JW. Deviance and Medicalization: from badness to sickness. Philadelphia: Temple University Press; 1992.

31. Baumann RJ, Wilson JF, Weise HJ. Kentuckians' attitudes toward children with epilepsy. Epilepsia. 1995; 36:1003-8. [PubMed: 7555950]

32. Austin JK, Shafer PO, Deering JB. Epilepsy familiarity, knowledge and perceptions of stigma: report from a survey of adolescents in the general population. Epilepsy \& Behavior. 2002; 3:368375. [PubMed: 12609335]

33. Kleinman A. The Social Course of Epilepsy - Chronic illness as social experience in interior China. Soc Sci Med. 1995; 41(3):451.

34. Bishop M, Slevin B. Teachers' attitudes towards students with epilepsy: results of a survey of elementary and middle school teachers. Epilepsy \& Behaviour. 2004; 5:308-15.

35. Jacoby A, Gorry J, Baker GA. Employers' attitudes to employment of people with epilepsy: still the same old story? Epilepsia. 2005; 46(12):1978-1987. [PubMed: 16393165]

36. Thapar AK, Stott NCH, Richens A, Kerr M. Attitudes of GPs to the care of people with epilepsy. Family Practice. 1998; 15:437-42. [PubMed: 9848430]

37. Link BG. Understanding Labeling Effects in the Area of Mental-Disorders - An Assessment of the Effects of Expectations of Rejection. Amer Sociol Rev. 1987; 52:96-112. 


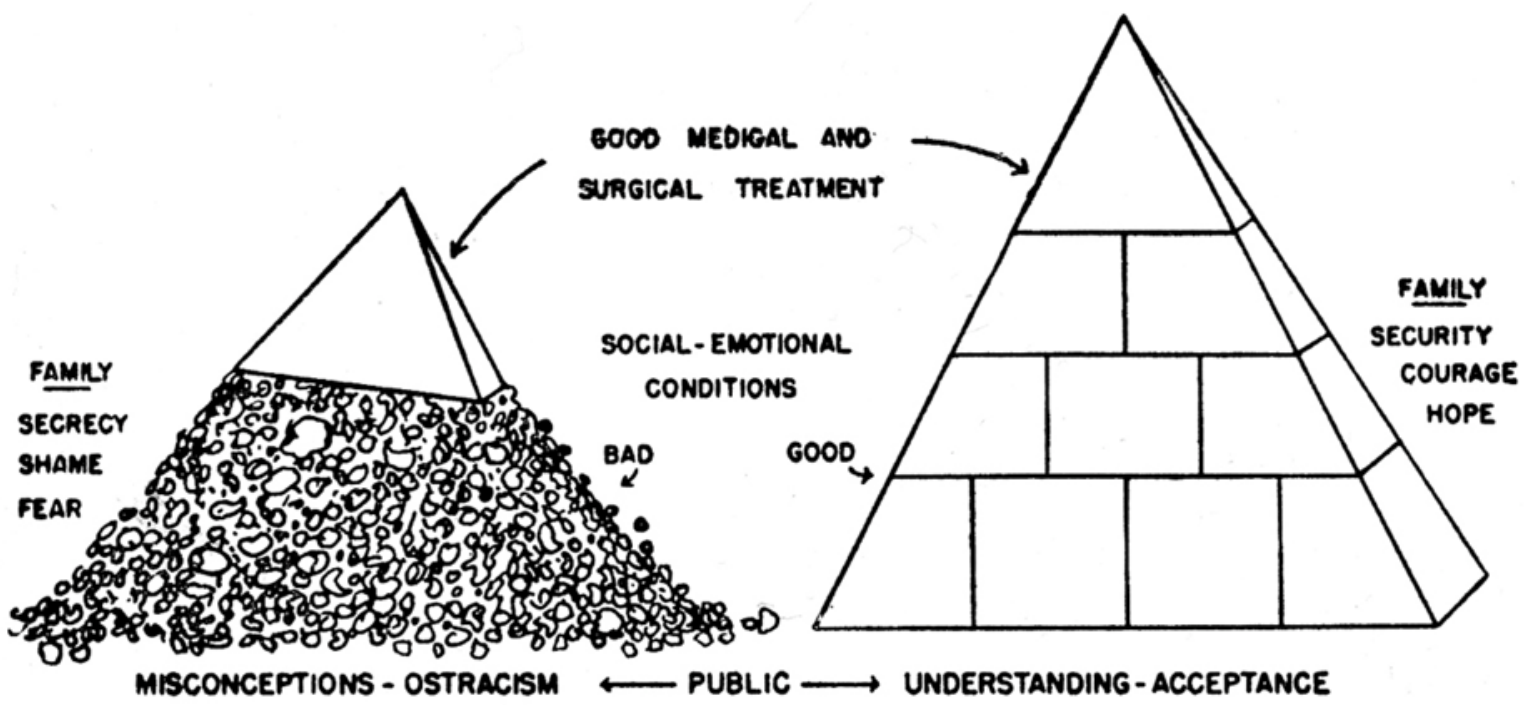

Figure 1.

Psychosocial issues of epilepsy (Lennox, 1960 [1]) 


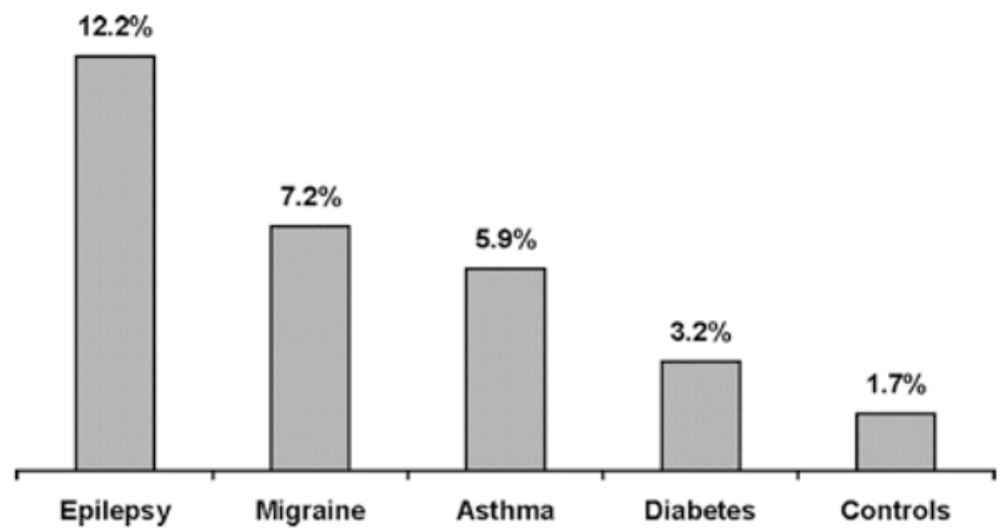

Figure 2.

The prevalence of bipolar symptoms in persons with epilepsy and other medical disorders and controls (Ettinger et al., 2005 [9]). 


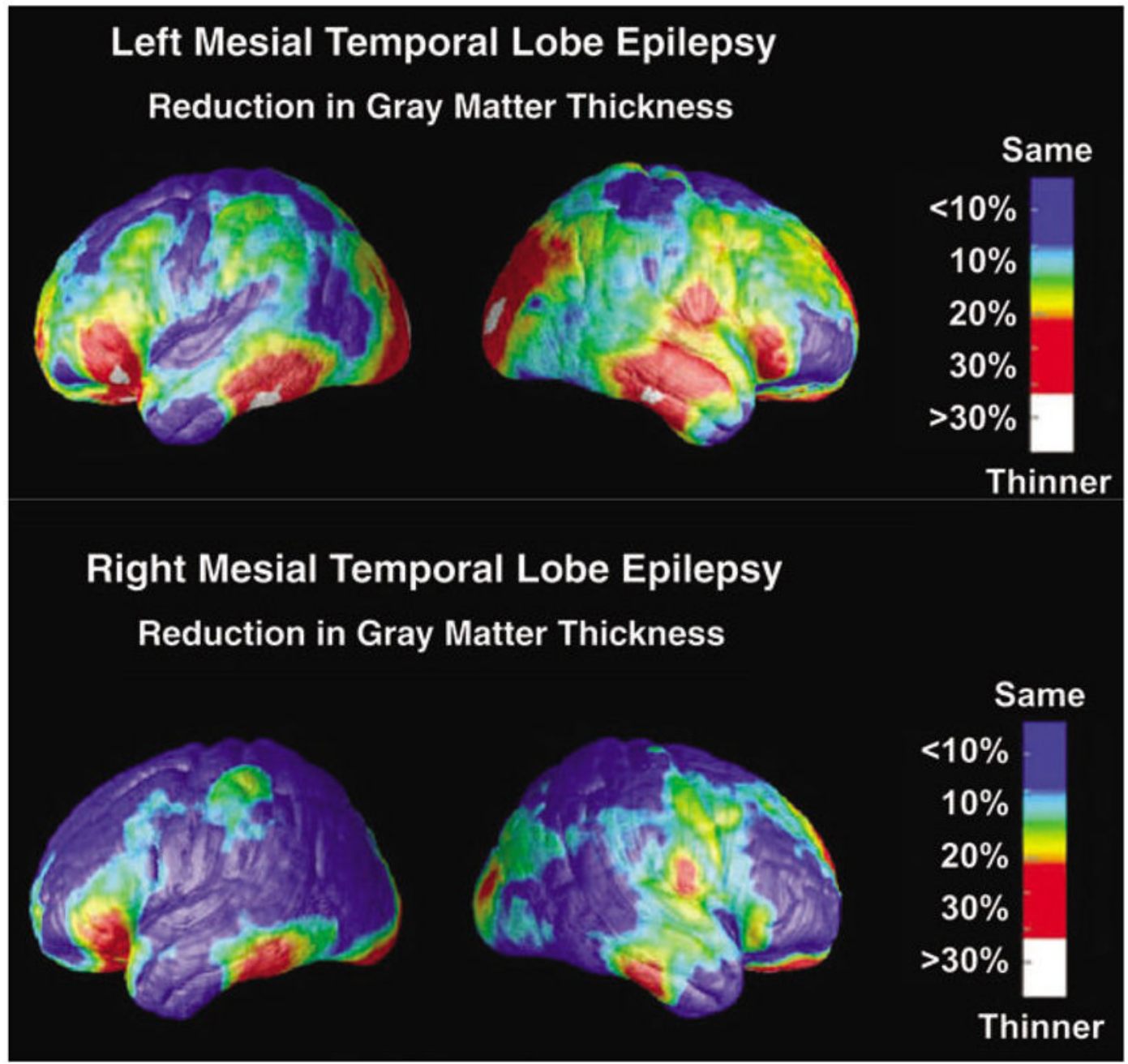

Figure 3.

Patterns of cortical thinning in unilateral mesial temporal lobe epilepsy (Lin et al, 2007 [13]). 


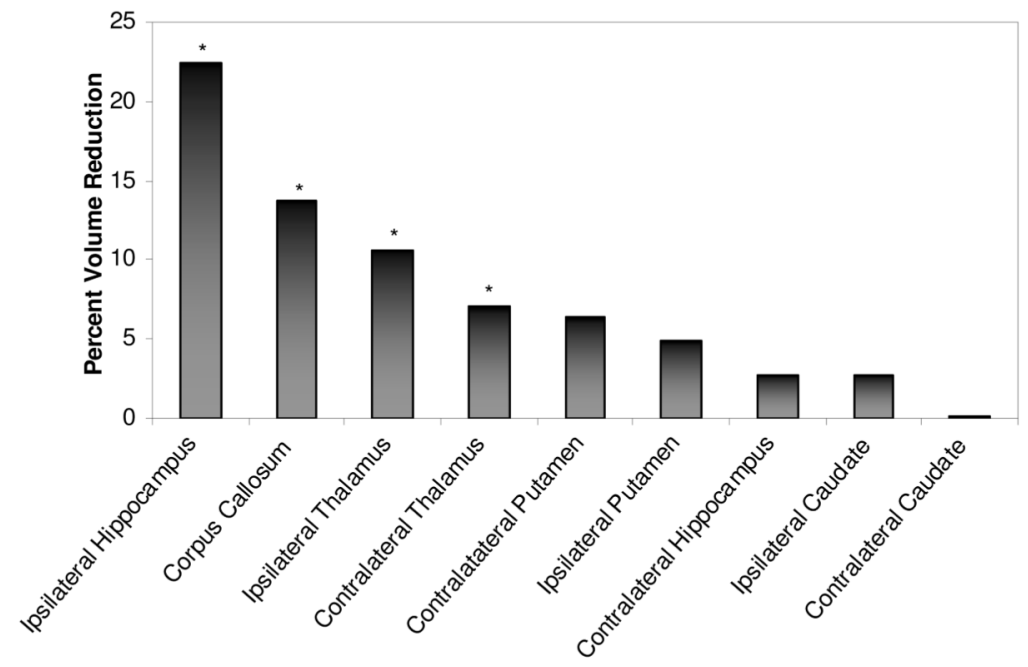

Figure 4.

Degree of atrophy across diverse regions both ipsilateral and contralateral to side of temporal lobe seizure onset (Pulsipher et al., 2007 [15]). 


\section{Table 1}

Lifetime prevalence of psychiatric comorbidity in persons with epilepsy compared to the general population. (Tellez-Zenteno et al., 2007 [8])

\begin{tabular}{|l|l|l|}
\hline \multicolumn{1}{|c|}{ Psychiatric disorder } & No epilepsy (N = 36,727) (95\% CI) & Epilepsy (N = 253) (95\% CI) \\
\hline Major depressive disorder (Lifetime) & $10.7(10.2-11.2)$ & $17.4(10.0-24.9)$ \\
\hline Mood disorder (Lifetime) & $13.2(12.7-13.7)$ & $24.4(16.0-32.8)$ \\
\hline Anxiety disorder (Lifetime) & $11.2(10.8-11.7)$ & $22.8(14.8-30.9)$ \\
\hline Mood disorder/anxiety disorder/dysthymia (lifetime) & $19.6(19.0-20.2)$ & $34.2(25.0-43.3)$ \\
\hline Panic disorder/agoraphobia (Lifetime) & $3.6(3.3-3.9)$ & $6.6(2.9-10.3)$ \\
\hline Suicidal ideation (lifetime) & $13.3(12.8-13.8)$ & $25.0(17.4-32.5)$ \\
\hline Any mental health disorder (lifetime) & $20.7(19.5-20.7)$ & $35.5(25.9-44.0)$ \\
\hline CI, confidence interval. & & \\
\hline
\end{tabular}




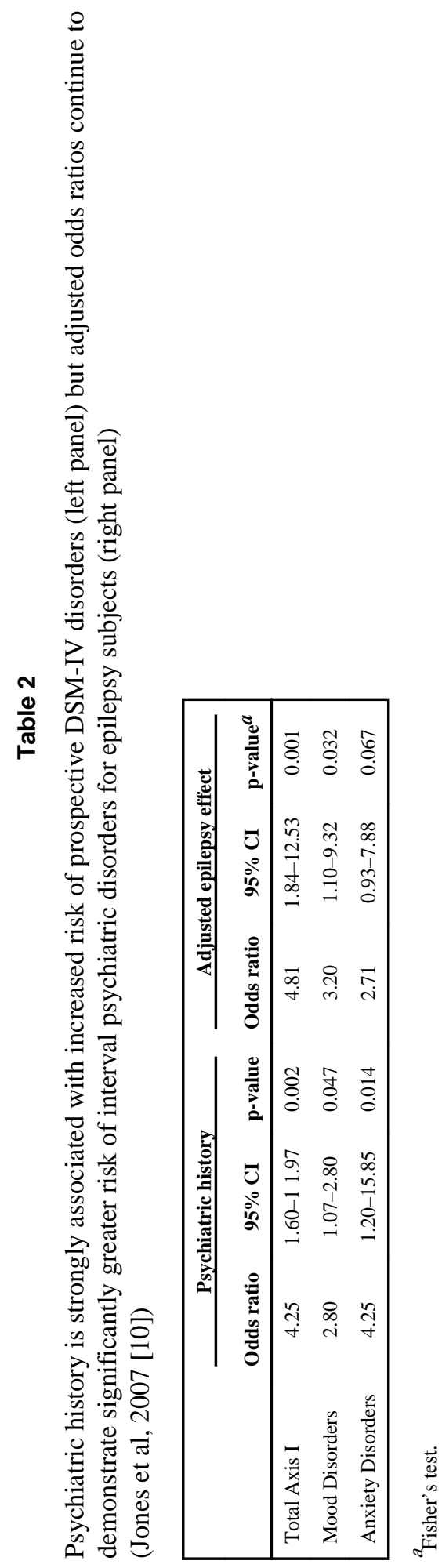

Epilepsy Behav. Author manuscript; available in PMC 2013 June 12. 
Table 3

Stigma scores on the three-point stigma scale $(n=338)$ Stigma in people with epilepsy (Birbeck et al, 2007 [21])

\begin{tabular}{lrrr} 
& Epilepsy group & Control group & P \\
\hline "Because of my (insert condition)..." & & & \\
I feel some people are uncomfortable with me & $105(62 \%)$ & $28(17 \%)$ & $<0.0001$ \\
I feel some people treat me like an inferior person & $101(60 \%)$ & $17(10 \%)$ & $<0.0001$ \\
I feel some people would prefer to avoid me & $98(58 \%)$ & $16(10 \%)$ & $<0.0001$ \\
\hline
\end{tabular}

Data are number (\%) of "yes" responses. 


\section{Table 4}

Economic comparisons $(\mathrm{n}=338)$

Economic and social comparisons of people with and without epilepsy (Birbeck et al, 2007 [21])

\begin{tabular}{|c|c|c|c|}
\hline Mean travel time to water if not in dwelling, $\min$ (SD) & $10.6(14.1)$ & $6.1(11.7)$ & $<0.0001$ \\
\hline Waste management & & & $<0.0001$ \\
\hline Missing & $1(1 \%)$ & $1(1 \%)$ & \\
\hline Toilet in dwelling & $25(15 \%)$ & $65(39 \%)$ & \\
\hline Toilet nearby & $13(8 \%)$ & $8(5 \%)$ & \\
\hline Pit latrine & $96(57 \%)$ & $85(50 \%)$ & \\
\hline Bush & $34(20 \%)$ & $10(6 \%)$ & \\
\hline Electricity in dwelling & $32(19 \%)$ & $86(51 \%)$ & $<0.0001$ \\
\hline Cooking source & & & $<0.0001$ \\
\hline Missing & 0 & $1(1 \%)$ & \\
\hline Electric stove & $29(17 \%)$ & $79(47 \%)$ & \\
\hline Wood & $85(50 \%)$ & $59(35 \%)$ & \\
\hline Charcoal & $55(33 \%)$ & $30(18 \%)$ & \\
\hline Wealth (mean kwacha) & 814273 (US\$232) & 1811142 (US\$517) & $<0.0001$ \\
\hline \multicolumn{4}{|l|}{ Healthcare use * } \\
\hline Prenatal care & $68(91 \%)$ & $76(97 \%)$ & 0.07 \\
\hline Home delivery & $30(40 \%)$ & $12(15 \%)$ & 0.0007 \\
\hline \multicolumn{4}{|l|}{ Food security } \\
\hline Eats two or more meals per day & $96(57 \%)$ & $167(99 \%)$ & $<0.0001$ \\
\hline Skipped meals in past week & $114(68 \%)$ & $84(50 \%)$ & 0.0001 \\
\hline$\geq 1$ day without food in past week & $94(56 \%)$ & $56(33 \%)$ & 0.008 \\
\hline Number of meat, poultry, or fish meals per month & $21(12 \%)$ & $33(20 \%)$ & $<0.0001$ \\
\hline Fewer meals in hunger season & $58(34 \%)$ & $33(20 \%)$ & 0.002 \\
\hline
\end{tabular}

Data are number $(\%)$ or mean (SD).

* Applicable population of women who had had at least one child ( $\mathrm{n}=75$ in epilepsy group, $\mathrm{n}=78$ in control group). 